\title{
APPLICATION OF PHYSICAL VAPOR DEPOSITION IN TEXTILE INDUSTRY
}

\author{
Pamela Miśkiewicz*, Iwona Frydrych, Agnieszka Cichocka \\ Faculty of Material Technologies and Textile Design, Institute of Architecture of Textiles, Lodz University of Technology, \\ 116 Zeromskiego Street, 90-924 Lodz, Poland \\ *Corresponding author. E-mail: pamela_miskiewicz@wp.pl
}

\begin{abstract}
:
Currently, scientists are striving to produce innovative textile materials characterized by special properties. Therefore, attempts have been made to use physical and chemical vapor deposition techniques to modify the surface of textile materials, i.e., nonwovens, fabrics, and knitted fabrics. By using these techniques for modifying the basic materials, researchers have obtained textiles with novel properties, which are used in shielding materials, textronics, or clothing, as well as in specialized accessories. The PVD process can be applied for almost all materials. The physical vapor deposition process allows for obtaining layers of different thicknesses and with various physical and chemical properties. This article is a review of the latest state of the art on the use of various methods of physical vapor deposition in textiles destined for different purposes.
\end{abstract}

\section{Keywords:}

Textiles, physical vapor deposition, material engineering, modification of textile materials

\section{Introduction}

Progress in the areas of manufacturing and increasing the service life of both structural elements and tools applicable in many areas of life is possible owing to the use of thin layer coating techniques, very often, of hard and wear-resistant ceramics. The extensive selection of currently available types of coatings and their application technology is the result of growing demand in the field of innovative methods of modification and surface protection of materials in recent years [1,2].

The processes of physical deposition of gas-phase coatings (physical vapor deposition [PVD]) are inseparably linked to the development of the vacuum technique, using - in their basic versions - two methods for changing the physical state of the coating material, namely, evaporation or sublimation (usually thermal), and spraying under the influence of methods other than thermal and physical stimuli. Originally, PVD techniques were used on an industrial scale mainly to apply shiny metallic coatings on reflectors and mirrors, as well as in laboratories, for uses ranging from the preparation of replicas mapping a specific surface structure to obtaining preparations used in electron microscopy transmission. The performance characteristics of the applied coatings depend on the individual physical properties and on proper adhesion to the substrate. Achieving a good coating adhesion to the substrate in standard methods of the PVD process requires very precise surface cleaning since the substrate temperature during the deposition of the coating material is not high. It is also very difficult to obtain a uniform thickness of coatings that are vacuum sprayed, especially for objects with complex shapes [3-5].
The evolution of traditional physical deposition techniques toward high-tech technologies was primarily aimed at disseminating and making available the physical methods that produce coatings characterized by a complex structure and chemical composition; therefore, coatings show high strength and hardness [6, 7]. Physical deposition from the gas phase consists of the formation of a coating on the substrate by the physical application of ions, atoms, or molecules. There are three key types of PVD based on the method of obtaining the deposited materials: sputtering, also known as ion plating or sputtering; vaporization; and spraying. Each of these processes is carried out in a vacuum from $10^{-5}$ to $10 \mathrm{~Pa}$.

Evaporation is the oldest and, at the same time, the simplest method of physical deposition. The method consists of heating the applied material, which takes place in high vacuum of about $10^{-3} \mathrm{~Pa}$ until it passes into the gaseous state, and the formation of coating on a specific substrate due to condensation.

The spraying process is used to apply coatings of significant technological importance. This process involves applying a chemical compound or metal in the vapor form with a high degree of ionization by atomizing a target (cathode), which is made of material deposited by using an ion stream of an inert gas, which is generally argon. The standard methods of direct spraying involving PVD use magnetron, cathode, and ion beam sputtering.

Sputtering is a combination of both evaporation and spraying. In order to carry out the spraying process, it is necessary to ionize the heat-evaporated material. Therefore, the material vapors are treated with additional physical forces, usually a 
glow discharge. A chemical reaction of the material vapors with gases that are dosed into the chamber can also be triggered $[2,7,8]$.

There are three stages in the formation of coatings in the process of PVD:

- obtaining vapors of the applied material (pure metal vapors and their alloys);

- transporting ionized or neutral vapors to the basic material;

- condensation of the vapors of the applied material on a specific substrate and an increase of coating thickness [9, 10].

The most important varieties (methods/techniques) of the PVD process are as follows:

- Activated reactive evaporation (ARE) method - this method is based on the use of a high-voltage electron gun to evaporate the material into an atmosphere of reactive gas.

- Biased ARE (BARE) method - this is an improvement of the ARE method and involves activation of reactive evaporation with the negative polarization of substrate. The main difference is the use of negative polarization of substrate causing the acceleration of ions involved in the crystallization of the coating.

- $\quad$ lonized cluster beam (ICB) method - this involves reactive deposition from ionized clusters, i.e., clusters of atoms, based on directing previously ionized clusters; these phenomena occur at supersonic speed on the ground.

- Thermoironic arc evaporation (TAE) method - during reactive evaporation, the electric shield, which is the source of vapors, is heated with an electron beam, thus forming the device anode. The ions emitted from the disk accumulate in a certain magnetic field and settle on the charged surface.

- Cathodic arc deposition (CAD) method - this method is also called cathodic arc evaporation (CAE) and is characterized by high ion and electron energy as well as a very high degree of plasma ionization.

- Reactive ion planting (RIP) methods - this method involves reactive sputtering, consisting of melting and evaporation of metals as a result of the use of high-voltage electron guns during the glow discharge occurring around a negatively polarized substrate.

- Hot hollow cathode deposition (HHCD) method - this is used to evaporate metals with low-voltage electrons.

- Pulsed plasma method (PPM) - This is also called pulsed plasma evaporation, which is the rapid pulsed evaporation from the solid state of the central electrode plasma due to the high current discharge of capacitors/batteries.
- Reactive magnetron sputtering (RMS) method - this method involves atomization of the material that is the substrate of the obtained coating, by the gas ions formed in the area between the plasma and the charge. The sprayed ions, on passing through the plasma, are subjected to ionization as well as reactions with the ions and atoms of the reactive gas, leading to coating deposition.

Techniques of PVD have many advantages, including the following:

- the high purity, efficiency, and ecofriendly nature of the process;

- the possibility of using substrates in the form of mainly pure gases and metals instead of their expensive, complex, and usually toxic chemical compounds;

- the possibility of producing composite layers (by the multiplex technology) in multisource devices;

- unlimited possibilities in the field of coating material production by free matching of substrates and, hence, wide possibilities related to the shaping of various functional properties of coatings, e.g., chemical, mechanical, tribological, physical, thermal, anticorrosive, and so on;

- the possibility of producing both nonstoichiometric and nonequilibrium coating materials with different properties.

The intensive development of PVD processes has contributed to the industrial use of extraordinary and special properties of coatings not only for coating tool materials but also in other areas of application [1, 3, 11].

\section{Application of PVD process in textiles}

Scientists are constantly working on the possibility of applying various PVD methods on the surface of textile materials (fabrics, nonwovens, and knitted fabrics). Research conducted so far to modify the surface of textile materials has been promising in terms of application and use in various scientific fields, e.g., textronics, material engineering, medical diagnostics, and electronics. Currently, a wide range of nanolayers, nanoparticles, and nanocomposites of various structures can be applied to fabrics, nonwovens, knitted fabrics, and even fibers, which allows for obtaining new properties that characterize the final textile product.

\subsection{Shielding properties}

Modern shielding materials are produced by PVD methods, which are most often applied with one or more conductive layers on nonconductive textile substrates, e.g., polyester (PES) or polypropylene (PP) nonwovens.

Ozimek and Wilczyński [12] used magnetron sputtering to obtain composite screens that suppress the electromagnetic field. Thin coatings of nickel and iron (Ni-Fe; $83 \%$ nickel and 
$16 \%$ iron) were produced and deposited on the surface of PP nonwoven of grams per square meter (GSM) number $160 \mathrm{~g} /$ $\mathrm{m}^{2}$. The spraying device was powered by an alternating current with an average frequency of $80 \mathrm{kHz}$ or negative current with a frequency of $160 \mathrm{kHz}$. The obtained coatings were characterized by a thickness in the range of $50-330 \mathrm{~nm}$. Ni-Fe coatings produced on the PP nonwoven showed an unevenness, which was caused by the penetration of metal between fibers constituting the substrate, while their advantage was a small number of delaminations and cracks. Very good adhesion of the produced coating to the substrate was also shown. This is very difficult to achieve using the other deposition methods. Moreover, the authors of the study found the optimal conditions under which the obtained electromagnetic screens show the best shielding properties.

Shielding research was also conducted by Bula et al. [13] using the cathodic sputtering method to obtain ultrathin metallic coatings on selected textile substrates. Copper was sputtered in tests for PP, PES, and viscose nonwovens. The samples obtained had a good shielding efficiency; the best sample was characterized by a PP nonwoven with copper coating. It has been found that the creation of possibly continuous metal coating on nonwovens is an essential condition for obtaining a good-quality material.

Proudnik et al. [14] studied, in a field of electromagnetic interference, the shielding properties of copper, titanium, and chromium coatings deposited on selected textiles by application of CAD (Arc-PVD). The shielding properties of selected metallized textiles in terms of protecting the human being against electromagnetic radiation were investigated. All measurements of the materials were made in the $8-12 \mathrm{GHz}$ band. The following fabrics were selected for tests: polyamide; a blend of PES, cotton, and heat-resistant "Arselon" fabric; PES; organza; and linen. Copper-coated fabrics suppressed electromagnetic radiation up to $5 \mathrm{~dB}$, samples of materials coated with titanium suppressed radiation up to $10 \mathrm{~dB}$, while those coated with chromium suppressed radiation up to $6 \mathrm{~dB}$. The reflection characteristic for copper-coated samples varies from -3 to $-11.5 \mathrm{~dB}$; for fabrics with titanium coating, it occurs in the range of -3.5 to $-10.5 \mathrm{~dB}$; and for fabrics covered with chrome, it ranges from -5.6 to $7.4 \mathrm{~dB}$. It has been shown that the metallization process of $\mathrm{CAD}$ of selected textile substrates with copper, titanium, and chromium allows for obtaining a material characterized by high mechanical strength, high damping value, and reflection in the $8-12 \mathrm{GHz}$ frequency band .

The transmission properties, only in the microwave range, of woven materials obtained by sputtering with titanium oxide can be used in protective clothing intended for emergency services, as investigated by Susek and Stanisławek [15]. The tests were carried out in two frequency ranges, namely, in the S-band with a frequency range of $2.8-3.2 \mathrm{GHz}$; and in the $\mathrm{X}$ band in the range of $8.0-12.0 \mathrm{GHz}$. The woven materials Natan $(75 \%$ Nomex, 23\% Kevlar, and 2\% carbon fiber) and Proton (58\% para-aramid, $40 \%$ poly(benzimidazole) [PBI], and $2 \%$ antistatic fiber) were used in the research. For the selected materials coated with a thin layer of titanium oxide, in the tests carried out in the S-band, no shielding effect was demonstrated; whereas in the case of the $X$ band, a reduction in the signal transmission was observed. Therefore, the textile materials selected for testing did not show the characteristics of shielding material.

Ziaja [10], in cooperation with the Textile Research Institute, produced composite shielding materials based on metallized PP nonwovens. Metallization was carried out using the pulsed magnetron sputtering technique with zinc, titanium, zinc, bismuth, and their oxides as targets. It has been shown that the structural and electrical properties of composites (metallized PP nonwoven fabric) are influenced by the parameters of the magnetron sputtering process: spraying time, the pressure and composition of the studied gases, power density emitted on the sprayed electrode, and the distance of the nonwoven from the target. Metallization of PP nonwovens as a result of the use of pulsed magnetron sputtering enabled the production of metallic coatings with excellent adhesion, which could not be obtained by using other deposition methods. Studies showed that the necessary, but sufficient, condition for achieving a good damping is a low value of surface resistance.

Another example is a composite formed on a nonwoven PP substrate by application of metallic layers. Using the pulsed magnetron sputtering technique, a coating of brass $(\mathrm{Cu}-\mathrm{Zn})$, titanium ( $\mathrm{Ti}$ ), and nickel (Ni) was produced on nonwoven PP substrate. Pulsed magnetron sputtering allows for obtaining coatings with a specific weight ratio, e.g., $\mathrm{Cu}-\mathrm{Zn} / \mathrm{Ti}$, or alternating application of selected metals or also their oxides, e.g., $\mathrm{Ni} / \mathrm{NiO} / \mathrm{Ni}$ or $\mathrm{Cu}-\mathrm{Zn} / \mathrm{Ti} / \mathrm{Cu}-\mathrm{Zn}$. Surface morphology showed that the sprayed material also settles on the surface of fibers that are inside the nonwoven fabric, leading to an increase in the shielding factor. It was found that increasing the number of coatings increases the shielding value. The composite shielding materials produced in the form of brass metallized PP nonwovens characterized by high attenuation coefficients (standard error [SE] $=30-50 \mathrm{~dB}$ ) are additionally sensitive to external environmental conditions. Furthermore, the shielding effectiveness of composites made of alternately sprayed $\mathrm{Cu}-\mathrm{Zn}$ and $\mathrm{NiO}$ coatings, which can decrease by up to $50 \%$ under the influence of aging, significantly limits their use. Therefore, the ideal solution would be to use a blend of brass and titanium. It has been shown that the value of the shielding coefficient depends on the titanium content in the $\mathrm{Cu}-\mathrm{Zn}$ coatings. The materials produced can compete with classic solutions [16].

The use of plasma metallization in the production of textile screens protecting against the electromagnetic field has been described by Ziaja et al. [17]. Metallization, as in the previous case, was carried out on the PP nonwoven fabric using the pulsed magnetron sputtering technique. A coating of zinc bismuth $(\mathrm{Zn}-\mathrm{Bi})$ was prepared on the fabric. There were no visible defects in the produced sample during sample bending. As a result of the tests, a screening efficiency $\sim 45 \mathrm{~dB}$ was obtained.

Jaroszewski et al. [18] conducted research related to obtaining conductive carbon coatings on PP nonwoven. Low-temperature plasma treatment was used to shield the electromagnetic field. Very good physical properties of coatings (i.e., adhesion and 
hardness) were demonstrated. An additional advantage noticed by researchers was the low cost of the deposition process.

\subsection{Electrical properties}

Conductive paths, glowing diodes, antennas, and all types of detectors used to record physicochemical changes in the surrounding environment are made on the surface of textile materials. The production of thin metallic coatings obtained on specific textile substrates and research on their properties are currently complex scientific issues.

Kubsz [19] worked on materials with special electrically conductive properties created using PVD methods. For testing, three flat substrates were selected, i.e., fabrics, nonwovens, and foils. The deposition process was carried out using copper. Using magnetron sputtering, copper coatings in the form of paths and contacts on structurally diverse substrates were produced. Substrates that could be used in textronic systems, i.e., smooth, homogeneous surfaces, such as PP films; extended structures of woven products, e.g., linen and PES; and nonwovens, e.g., PP and glass nonwovens, were selected for research. Electroconductive properties were obtained for the coatings formed on the PP film, PP, and glass nonwovens, as well as on the surface of PES/BA fabric. The difference in the quality of paths created on such substrates is the result of the fabric's surface topography, more precisely, the applied type of weave. The produced coatings, to be able to perform their role of conducting paths or microcontacts, should have electroconductive properties, durable in the processes of use.

Korzeniewska et al. [20] studied the resistance of metallic coatings used in textronic systems subjected to mechanical deformations. A composite substrate, Cordura, was used, consisting of nylon fibers, which were coated with polyurethane (PU) foil. Further, $99.9 \%$ of pure silver was used in the PVD process. Coatings $\sim 300 \mathrm{~nm}$ thick were obtained. As a result, thin electrically conductive coatings were obtained by using the physical vacuum deposition process without protecting their surface against destructive factors, which were characterized by high resistance to cyclic mechanical deformations. An increase of the high resistance is visible after the fifth layer's extension. It was found that such structures can form flexible components that can be used in many areas of flexible electronics, textronics, and electrical engineering.

Koneczny [21], together with Pawlak and Korzeniewska, in his doctoral dissertation, worked on "Properties of thin conductive layers produced on composite textile structures using thermal vacuum evaporation methods". These authors worked on depositing thin conductive coatings on selected textile materials. In the first stage of research, an attempt was made to produce thin coatings on fabrics that differed in their GSM number, fiber type, weave, and weft and warp density. For tests as a background, the following were selected: viscose, silk cotton, PES, and blends of PES and viscose, wool and PES, PES and polyamide, as well as PES, viscose, and elastane. Metals, i.e., gold, copper, and silver, were used for deposition. The test results were unsatisfactory, because the electrical conductivity of the produced metallic coatings appeared locally and depended to a high degree even on slight deformations of the substrates that were selected as fabrics. In the further stage of research, the author of the doctoral thesis proposed the deposition of thin metallic coatings on composite textile materials due to the more stable and less extensive spatial structure compared to fabrics. For the next stage of research, Goratex was selected as a single-layer nylon fabric with a Teflon coating; Cordura was selected as a nylon fabric with a PU coating; and a membrane made of PES fabric with a Teflon coating containing nanofibers. The final result confirmed the excellent dielectric properties of the materials selected for testing.

Pawlak et al. [22] used the coated composite material Cordura and the same method of thermal vacuum vaporization for the deposition of pure gold and silver coatings, as done previously. Modification of the selected textile material using thermal vacuum evaporation significantly improved the electrical properties and the strength of the electrically conductive coatings that were prepared on the selected textile substrate. The suitability of the metallic coatings produced on the Cordura composite for various textronic applications was determined.

Pawlak et al. [23] undertook the use of PVD to obtain conductive coatings on the surface of selected textiles. Research included the production of metallic coatings on selected samples of textile products. Metals, i.e., silver and gold, were used in the vacuum deposition process. Twill weave cotton fabric, plain weave PES fabric, and twill fabric made of blend of PES with cotton were selected for the study. Fabrics differed in the GSM number, thickness, number of twists, and the weft and warp density. Research was divided into three stages. The first stage involved performing preliminary experiments to obtain the surface electrical conductivity of the metallic coatings vacuumdeposited on selected fabric variants. The second stage was related to the deposition and testing of conductive coatings on fabrics made in the first stage. The third stage consisted of process optimization, i.e., conducting the deposition process under conditions determined based on results obtained in the second stage. Work carried out to produce metallic coatings on textile substrates using variable vacuum deposition conditions showed the influence of substrate on the quality of metallic coatings. The best results of electrical conductivity were obtained in the third stage for cotton fabrics and a blend of PES and cotton.

The functionalization of a nonwoven surface modified by sputtering aluminum on its surface was carried out by Deng et al. [24]. Aluminum was deposited on the commercial surface of PES nonwoven fabric (polyethylene terephthalate, abbreviated as PET). The electrical resistance of sputtered aluminum was significantly reduced, while the deposited aluminum coating significantly affected the nonwoven fabric's surface. Nonwoven materials thus produced can be used in the production of conductive screens or packaging [24].

Silva et al. [25] deposited conductive materials on selected textile and polymeric substrates. Kapton HN polyimide film was the reference material for the substrate used in tests. Furthermore, elastic textile materials were selected as 
substrates, namely, natural and synthetic leather, elastic fabric with a PU coating (which was of matt color), fabric with a double-sided PVC coating, fabric with a PVC coating, and fabric with PU coating. A typical method of PVD was thermal evaporation, which produced a 300 -nm-thick aluminum coating on the substrate's surface. Among the textile materials, the lowest values of electrical resistance were achieved by the fabric with the PU coating and the fabric with the doublesided PVC coating, while the natural leather and the fabric with PVC coating did not show conductive properties, which may be caused by the bonding of the aluminized film with the substrate surface. On testing the mechanical properties, it was found that the fabric with the PVC coating, the fabric with PU coating, and the fabric with the PU coating are highly flexible. The fabric with double-sided PVC coating was characterized by poor adhesion to the substrate. Energy-dispersive X-ray (EDX) spectrometry showed oxygen, aluminum, chlorine, carbon, and silicon in the coating material, with chlorine and carbon pointing to the coating PVC material. It was found that textile materials with very low flexibility, i.e., PVC materials, can constitute flexible substrates for the integration of electronic circuits. Fabrics coated on both sides with PVC were chosen as the best textile materials. Selected textile materials are used in textile applications, but they are not suitable for use as the basic material for clothing.

Yuan et al. [26], in further research, focused on the electrical and optical properties of PES fabric covered by magnetron sputtering with a composite of silver and titanium dioxide. The complex coatings of silver and titanium dioxide $\left(\mathrm{Ag} / \mathrm{TiO} \mathrm{O}_{2}\right)$ were then deposited on the PES fabric using direct current (DC) magnetron sputtering and radiofrequency (RF) alternating current magnetron sputtering techniques. The process of preparation of $\mathrm{Ag} / \mathrm{TiO}_{2}$ composite coatings was as follows: a thin silver coating was first deposited on the PES basic fabric by means of magnetron sputtering with a constant current (DC), and then another thin coating of titanium dioxide was further deposited on the fabric previously coated with silver by spraying magnetron radiofrequency (RF) alternating current. Compared to the original fabric samples, the modified fabric showed improved antiultraviolet (anti-UV) and antistatic properties of [26].

Depla et al. [27] worked on the possibility of using RMS to deposit thin coatings of metals, namely, aluminum, copper, and titanium, as well as thin coatings of metal oxides, i.e., aluminum oxide $\left(\mathrm{Al}_{2} \mathrm{O}_{3}\right)$ and titanium oxide (TiO), on woven and nonwoven textile substrates. Researchers used plain weave cotton fabric, plain weave PP fabric, and needle-punched PES nonwoven fabric. RMS has been confirmed to open up new possibilities for the production of advanced fabrics.

Wei et al. [28] worked on the characteristics of copper (Cu)coated nonwoven fabric obtained as a result of sputtering. The tests were carried out on a PP nonwoven of GSM number $50 \mathrm{~g} /$ $\mathrm{m}^{2}$ and thickness of $0.35 \mathrm{~mm}$. High-purity copper was sprayed on the samples. Thus, 20-, 50-, and 100- nm-thick coatings were produced on the surface of the three nonwoven samples. The sputtered copper $(\mathrm{Cu})$ coating significantly affected the surface properties of the PP fibers. The increase in coating thickness from $50 \mathrm{~nm}$ to $100 \mathrm{~nm}$ resulted in the compact distribution of copper clusters on the fiber's surface. The use of EDX spectrometry showed that, after sputtering the 20- nmthick copper coating, the surface of the nonwoven fabric consisted mainly of a significant amount of copper $(\mathrm{Cu})$. The coated nonwoven fabric showed significant improvement in terms of protection against UV radiation and visible light. The best resistivity result was observed for the coating of thickness equaling $100 \mathrm{~nm}$.

The magnetron sputtering method was also used to obtain electrically conductive metal transmission lines on selected textile substrates. The tests were carried out on PP spun-bonded nonwovens and needle-punched polyamide nonwovens, which differed in GSM number and thickness, while the sprayed material was copper. In order to obtain a smooth surface, the nonwoven fabric was melted by pressing with a polyolefin film for 120 seconds. None of the tested variants was resistant to the abrasion test. The tests carried out on the PP spun-bonded nonwoven fabric showed that electrically conductive copper coatings with surface resistance $\sim 0.2$ were obtained. The created transmission lines could be used primarily in protective clothing intended for emergency services [29].

\subsection{Antibacterial properties}

Antibacterial textile products, i.e., hygienic clothing, must meet specific requirements, such as effectiveness against wide range of fungi and bacteria, stability after washing, costeffectiveness, harmlessness to the consumer's health, and composed of substances that do not cause adverse reactions on the body.

Scholza et al. [30] tested silver, gold, platinum, platinum/ rhodium, and copper coatings sprayed on textile substrates by using magnetron sputtering and then compared them in terms of their binding strength and antimicrobial properties. All the coatings produced showed antimicrobial properties, however, at different levels of effectiveness. The copper coating was the most effective while testing for protection against fungi and bacteria. The silver coating was effective against bacteria, but in the case of fungi, its functionality was limited.

Castro et al. [31] researched the application of copper $(\mathrm{Cu})$ by using DC magnetron sputtering for the inactivation of Escherichia coli on cotton fabrics. Studies showed a higher roughness of cotton fabric with copper coating compared to that of pure cotton fabric. The application of copper by DC direct magnetron sputtering allowed for a thin, metallic, and translucent copper coating with a gray-brown color and moderate hydrophobic behavior, determined by contact angle measurements. In the case of the cotton fabric, a strong bonding of the coating with the substrate was noticed. Spraying carried out for 40 seconds enabled an optimal balance of film thickness, roughness, and crystallite size.

Obtaining increased antibacterial effectiveness and durability was the goal of further research led by Chen et al. [32]. The high-power pulsed magnetron sputtering method deposited the silver coating on the surface of a PES fabric in such a 
way that the fabric was evenly coated and a good adhesion of silver coating to the substrate was achieved. The coated fabric retained its original mechanical properties and showed better antimicrobial efficacy than the uncoated fabric. The selected deposition method can be used to produce fabrics with antibacterial properties.

Chen at el. [33] continued the research into obtaining a brass coating on the same textile substrate by using the previously described technique. An antibacterial and corrosion-resistant brass coating was produced on the PET fabric. The coated fabric had an excellent durability after washing and abrasive tests. Additionally, the modified fabric has been shown to retain its mechanical properties and provide effective antibody properties.

\subsection{Thermal properties}

Heat transfer through textile substrates is a complex and complicated phenomenon. Zhai et al. [34] attempted to investigate how the use of magnetron sputtering on protective fabrics will affect their thermal properties. On the surface of aramid fabric, the following coatings were added: aluminum (Al) coating; a two-layer coating of aluminum (Al) and silicon dioxide; $\left(\mathrm{SiO}_{2}\right)$ and a three-layer coating of silicon dioxide $\left(\mathrm{SiO}_{2}\right)$ /aluminum $(\mathrm{Al}) /$ silicon dioxide $\left(\mathrm{SiO}_{2}\right)$. The metal coating (aluminum) on the fabric surface was deposited by the DC magnetron sputtering technique, while the nonmetallic coating (silicon dioxide) was obtained by the RF magnetron sputtering technique. It was observed that all three types of coated structures on the surface of the aramid fabric form continuous and dense layers. A single Al film yielded the smoothest and finest metal particles on the surface. The $\mathrm{SiO}_{2} / \mathrm{Al}$ doublelayer coating was smooth, but with larger particle sizes than the single-layer coating, while the three-layer coating had the worst surface because of roughness. It was shown that the resistance to heat radiation improved for all the three types of coating applied to the aramid fabric. As a result, the reflection coefficients of $\mathrm{SiO}_{2} / \mathrm{Al} / \mathrm{SiO}_{2}$ and $\mathrm{SiO}_{2} / \mathrm{Al}$ and single $\mathrm{Al}$ were $64.97 \%, 57.38 \%$, and $51.59 \%$, respectively.

Tests for the thermal and physical properties of the nylon fabric subjected to metal sputtering, i.e., aluminum, copper, and nickel, were conducted by Han and Kim [35]. The basic material was nylon. Mylar foil was also used, one side of which was conductive, when spraying the aluminum. The thickness of the deposited metal coatings was $\sim 600 \mathrm{~nm}$. Examination of the EDX spectrometry results showed that the surfaces of the tested samples had $>80 \%$ content of the individual metals. Moreover, it has been shown that if the garment is made of metal-coated nylon fabric, this does not affect the transmission of water vapor in the human body. Of all fabrics, the conductive fabric showed the worst permeability. The shear test results were comparable for both uncoated and coated samples. The conductive fabric showed the highest stiffness, because it was densely woven. The coated fabric was stiffer, as shown by the bend test. It was assumed that due to the high bending stiffness, the conductive fabric will show a low drapability, especially since the Mylar also has high stiffness [35].
Heat transfer in the aluminum sputtered on textile materials has been studied by Han et al. [36]. Aluminum was sprayed on four textile substrates, namely, nylon, PES, cotton blend with 50/50 PES, and PU with shape memory, which was produced by the authors and referred to as SMPU (shape memory PU). The thickness of coating applied increased linearly with the spraying time. Aluminum was only sprayed on one side of the fabric. It was confirmed that basic fabrics and fabrics modified with aluminum coating showed different values of thickness, thermal conductivity, and heat emissivity. To determine the heat transfer properties, aluminum was sprayed for 10 minutes on the selected samples. The heat transfer coefficient of the aluminum coating increased with the thickness of coating. A cotton/ PES blend (50/50) showed the lowest value of heat transfer coefficient.

\subsection{Other properties}

The following section describes the other possible methods of PVD application involving the modification of fabric surface or nonwovens in order to improve their selected properties.

Meriç [37], in her master's thesis, wrote about the use of antistatic metal-coated fibers using the inverse magnetron sputtering method (inverted cylindrical magnetron sputtering system). She conducted research using silver. Applying an inverted cylindrical magnetron sputtering system, different fibers of different diameters were coated. A silver coating was applied to PP fibers with a diameter of $400 \mu \mathrm{m}$; then, the fiber diameters were reduced to $300,200,150,125$, m and $85 \mu \mathrm{m}$. In order to test the antibacterial properties, the silver-coated fibers were woven into fabrics by hand. The optimum thickness of the thin coating was $\sim 150 \mathrm{~nm}$, because no cracks were observed at this thickness. These fabrics have the potential to be used in electromagnetic shielding and absorbent materials.

Chodun et al. [38] worked on multilateral metallization of textiles using the magnetron system with a grounded cathode. The source of plasma was the magnetron with a grounded cathode and positive anode. Samples of glass and cotton fabrics selected for testing were deposited with titanium (Ti) and titanium nitride (TiN) coatings of thickness in the range of 2-3 $\mu \mathrm{m}$. The samples were covered with a one-sided layer using standard magnetron sputtering and covered on both sides by modifying the previously used method using the grounded cathode. Both right and left sides of the glass fabric were subjected to optical transmission and reflection in the range up to $2,500 \mathrm{~nm}$. It was shown that there was no significant difference between the first and the other side of the fabric, but different thicknesses of the coatings were noticed on both sides. The reflection and transmission spectra of both sides of the glass fabric covered with titanium and titanium nitride coating showed a reduction in transmission and scattering of electromagnetic radiation. In addition, the titanium coating was found to have lower transmission and was more reflective. When using the magnetron sputtering in association with a grounded cathode, the particles penetrated inside the textile structures that were coated on both sides. The glass fabric was coated on one side with 2- mm-thick titanium and 
titanium nitride coatings. Cracks and delamination were visible. No cracks were observed in other textile areas.

Vančoa et al. [39] worked on the application of coatings produced by the PVD process on fabrics composed of natural fibers. The tests were carried out on cotton fabric using PVD technology, i.e., vacuum deposition was conducted using a Flexicoat 850 coating machine, and the deposited metal was silver. Because cotton fabric is characterized by an uneven structure, the deposited coatings had an uneven thickness. Static tensile strength tests show that the coated cotton fabric is stronger than the uncoated one. The authors are constantly conducting new research on this subject, striving to produce a material or composite with a wide range of applications.

Dietzel et al. [40] investigated coatings on polyamide fabrics obtained by the PVD process. The tests were carried out on the fabric made from polyamide 66 . The fabric was deposited with titanium nitride and titanium carbide layers using the $C A D$ method with an industrial HTC 1000/4 ABS device. It has been shown that the coating obtained as a result of the PVD process may have different surface properties depending on the process conditions. Both carbon and nitrogen react with the polymer surface, which leads to the formation of new structures. The use of various reactive and noble gases in the production process leads to different levels of coating adhesion. Nitrogen results in better adhesion than, e.g., argon plasma.

The properties of PP nonwoven fabric modified using copper, zinc oxide, and polytetrafluoroethylene ion sputtering were studied by Wei et al. [41]. Functional coatings had formed on the surface of the nonwoven fabric. Moreover, it was found that the copper coating significantly improved the surface conductivity of the modified material; the zinc oxide coating significantly increased the absorption in the UV range by the nonwoven, while the polytetrafluoroethylene coating enhanced the hydrophobicity of the nonwoven. The ionic coatings made of metallic materials, metal oxides, and polymeric substances enable the surface functionalization of selected textile materials, as well as facilitating a wide range of applications.

The use of magnetron sputtering to deposit PET indium tin oxide (ITO) on the surface of the PET nonwoven fabric, i.e., a ternary composition containing indium, tin, and oxygen, was studied by Wei et al. [42]. ITO with a content of $97 \%$ indium and $3 \%$ tin dioxide was used in the study. Different deposition conditions were applied and the effect on fiber morphology was studied. Using different spraying temperatures, it was shown that an increase in temperature improves the adhesion of the produced coating to the PET nonwoven fabric. However, very high temperatures can lead to its damage.

Lee et al. [43] researched aluminum deposition by DC magnetron sputtering on chemically recycled PET (CR-PET) fabrics. The tests were carried out on $100 \%$ CR-PET fabric of GSM number $187.6 \mathrm{~g} / \mathrm{m}^{2}$ and thickness of $0.15 \mathrm{~mm}$. Chemical recycling of PET based on degradation at the molecular level is based on an interesting process of reproducing the PES resin of high-quality products, i.e., textile fibers. However, no research has yet been done on CR-PET fabrics. Pure aluminum $(99.9 \%)$ was used in the tests. As a result, it was shown that the wettability of CR-PET fabrics coated with aluminum decreased with increase in the deposition time and spraying power. The reflection of light by aluminum-coated CR-PET fabrics was the maximum, whereas the thermal insulation properties improved with increasing deposition time.

The purpose of this article, which is a review of the state of the art, is to show the possibility of using various methods of the PVD process to modify the surface of textile materials. The smallest group of publications is that related to modification aimed at improving the thermal properties of materials. Therefore, Miśkiewicz et al. [44-46] are working on modifying basalt fabric's surface by using the magnetron sputtering method to place it in the palm of a glove to protect against high temperature and hot factors. To date, chromium, aluminum, and zirconium (IV) oxide coatings of various thicknesses have been deposited on the basalt fabric surface. The modified fabric was subjected to tests for resistance to contact heat and radiant heat. In the case of contact heat resistance, tests were carried out for the contact temperatures of $100^{\circ} \mathrm{C}$ and $250^{\circ} \mathrm{C}$. However, no modified sample reached the first level of protection efficiency. The zirconia-coated basalt fabric achieved slightly better contact heat resistance results than the metal-coated basalt fabric. In the case of radiant heat resistance, better results were noted for fabric samples with metal coating (chrome, aluminum) due to the silver color of the modified sample than with ceramic-coated fabric (zirconium (IV) oxide). The authors found that direct application of selected coatings to the basalt fabric only slightly improves the selected protective properties; hence, they have begun work on basalt composite [47].

\section{Conclusions}

Currently, the development of new technologies and the combining of scientific disciplines allows for the manufacture of new innovative textile materials. The use of various methods of PVD to modify the surface of textile materials (fabrics, nonwovens, and knitted fabrics) has led to the production of new materials with new properties, which are used in various fields, such as electronics, textronics, materials science, and medicine. The interest of researchers in combining the PVD process with textiles is visible as an increasing number of scientific publications are available on this subject. Table 1 shows the most important information obtained from the literature review. In the future, metallized textiles are expected to be used in personal protective equipment used in hot work environments and for reflecting UV radiation, as a thermal covering for glass or basalt fabrics to increase their thermal insulation, as well as for textiles resistant to static electricity accumulation, e.g., special-purpose fabrics properties designed for people from the electronics industry. 


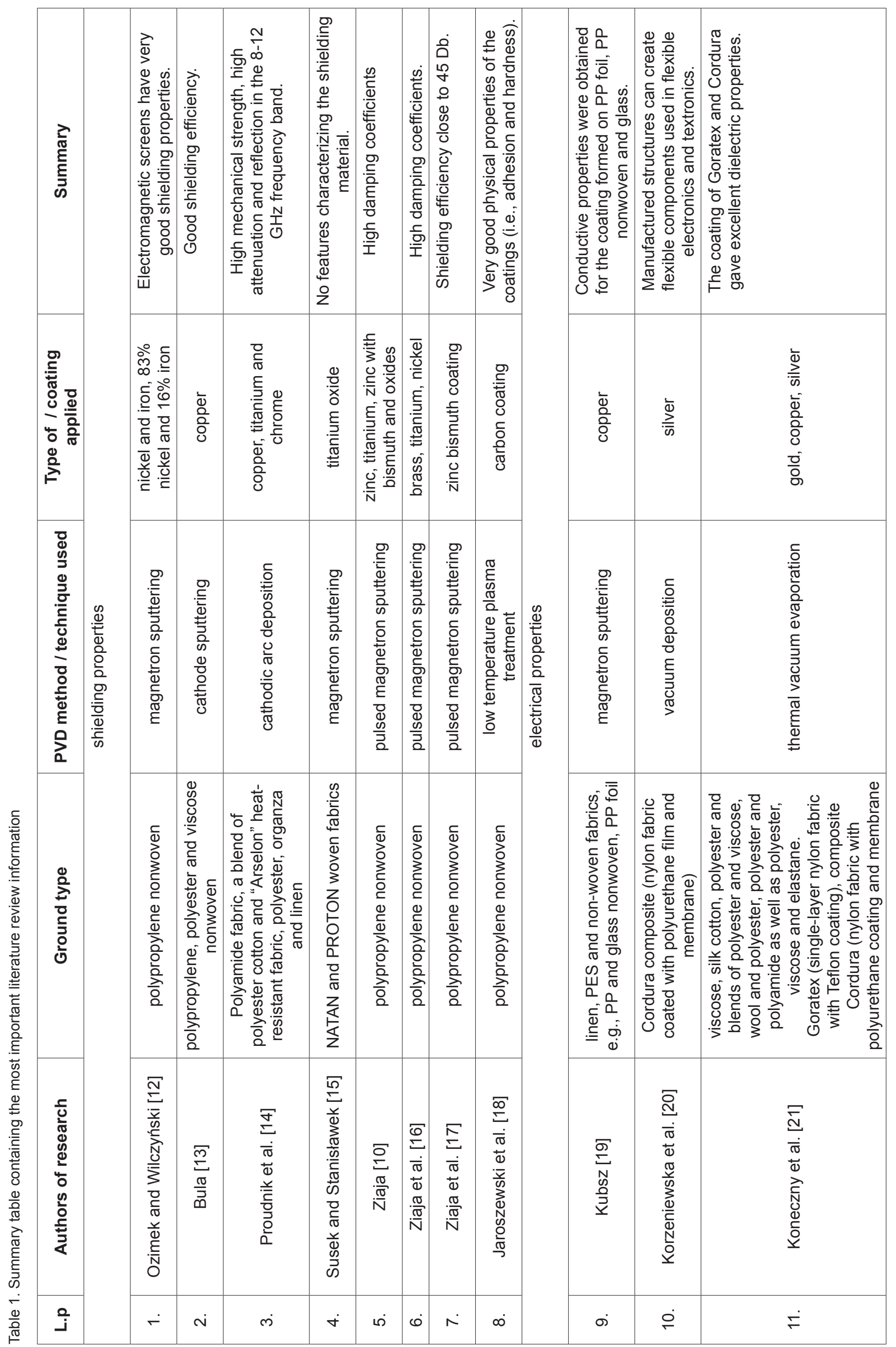




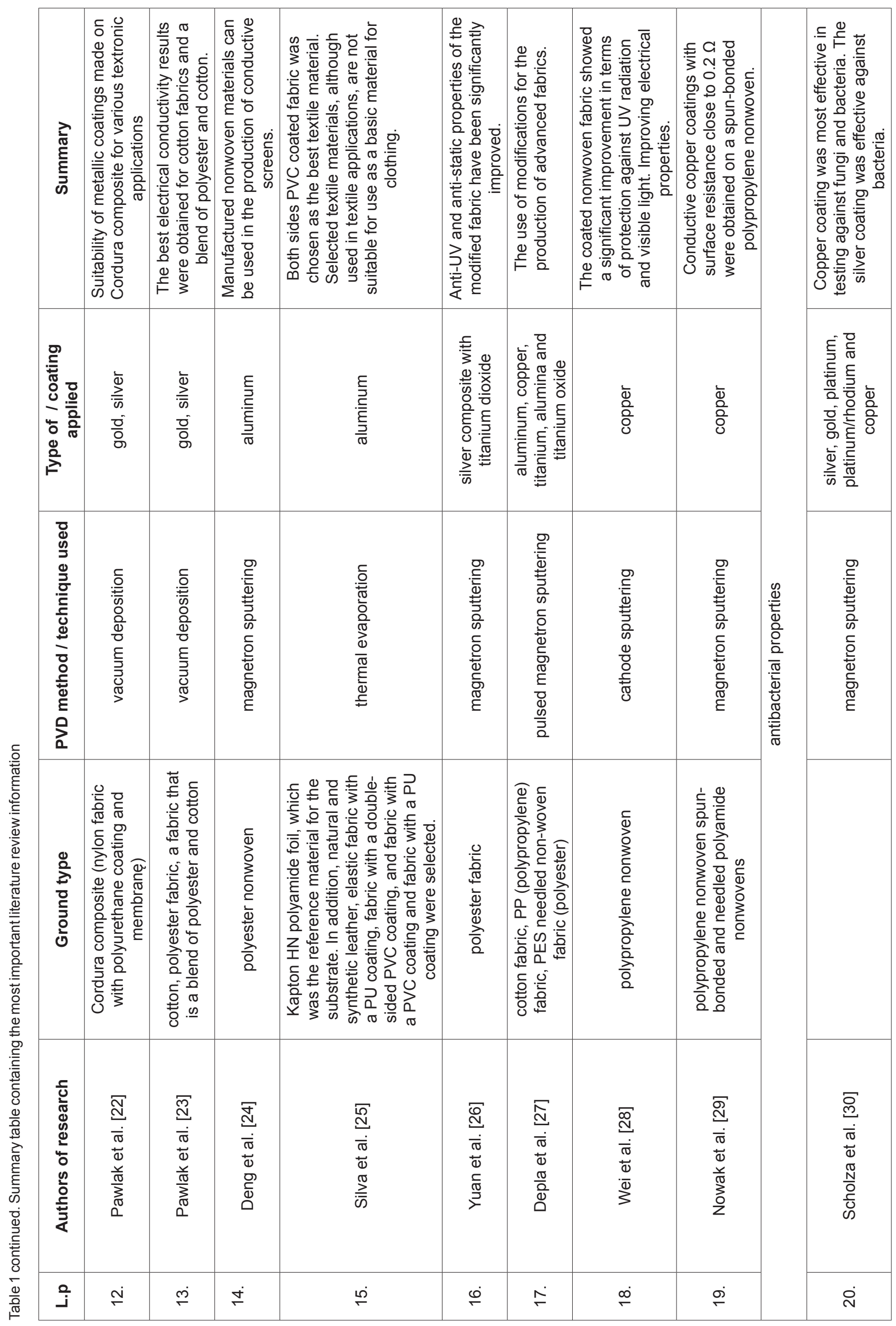




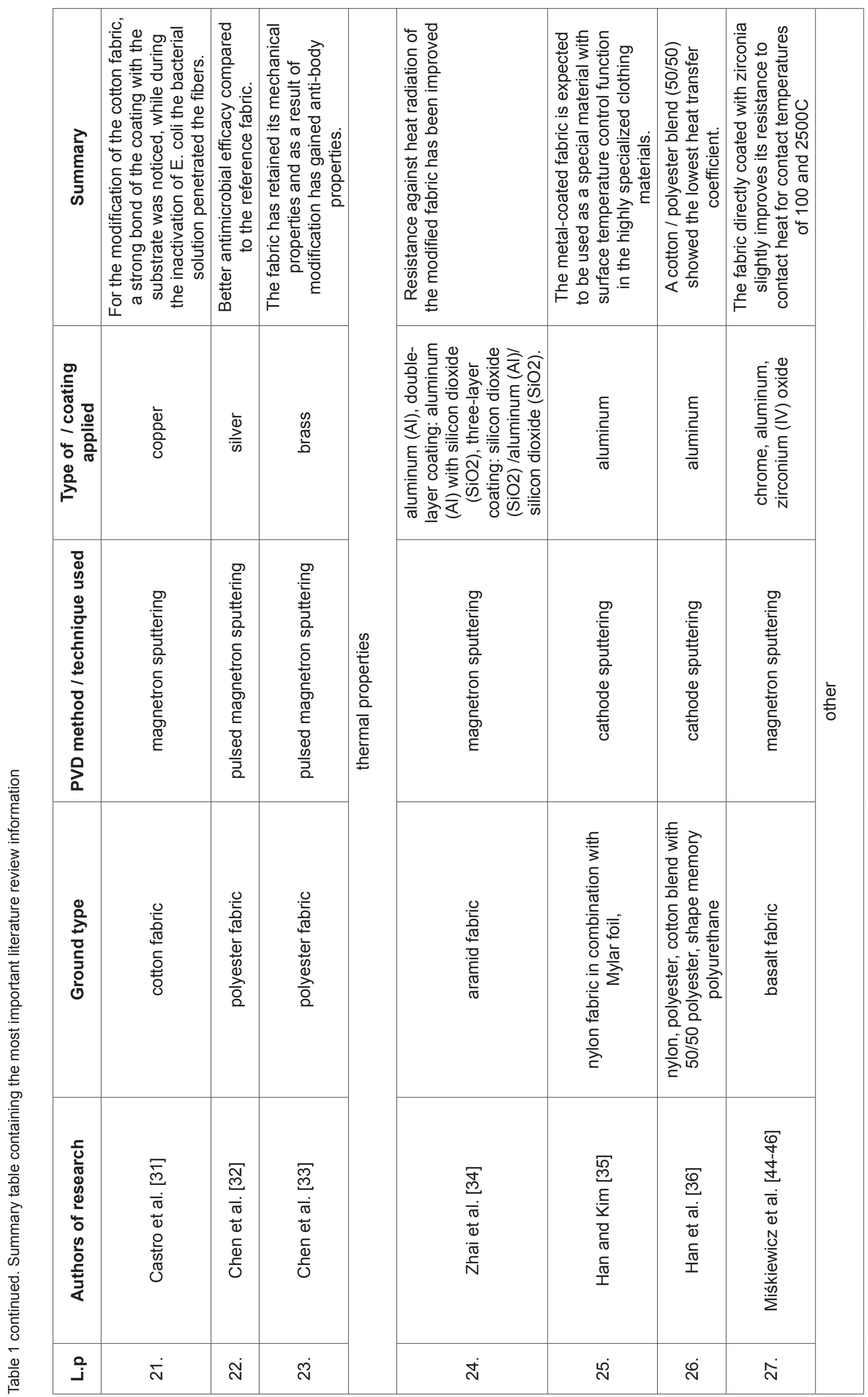




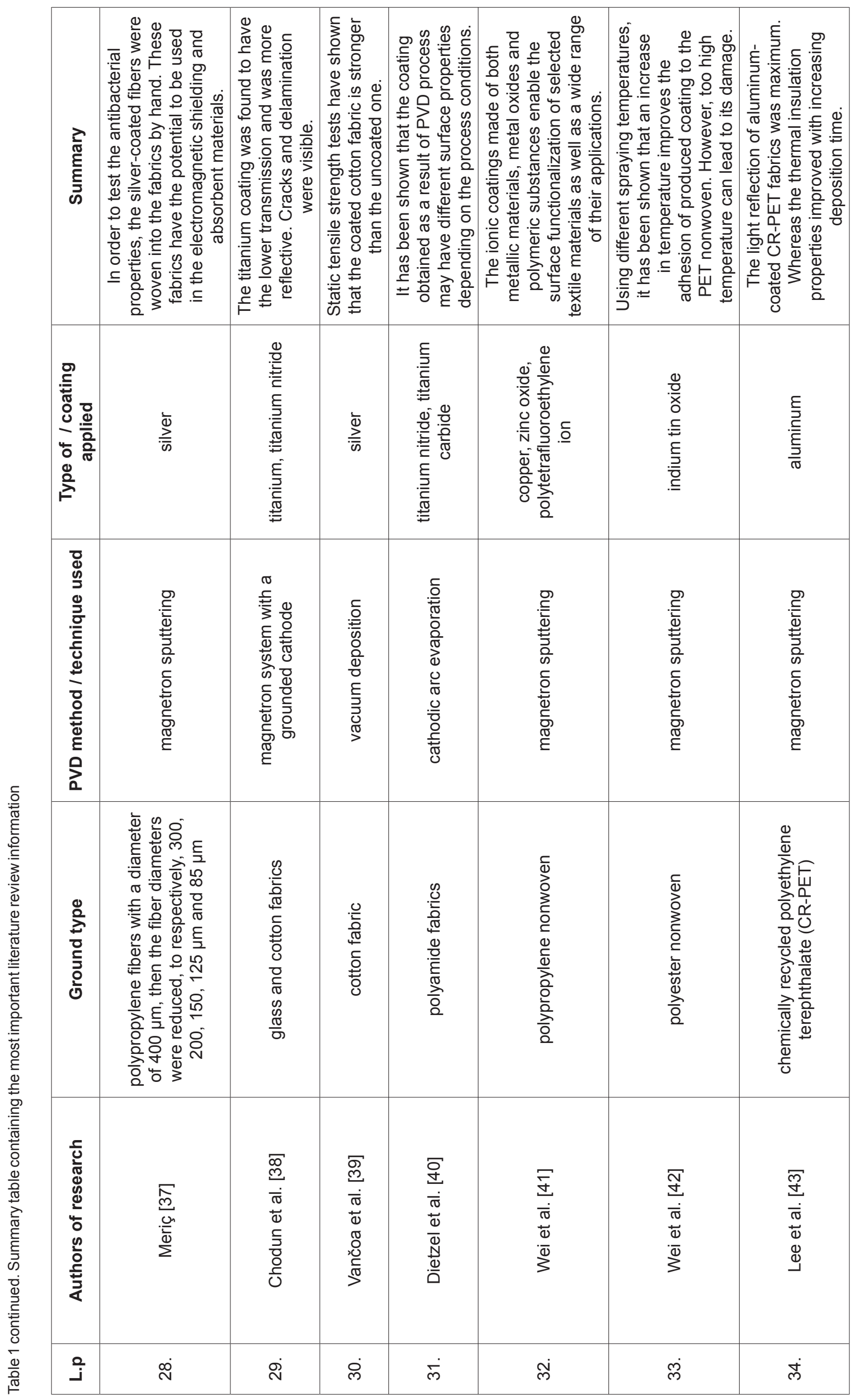




\section{References}

[1] Shahidi, S., Moazzenchi, B., Ghoranneviss, M. (2015). A review - application of physical vapor deposition (PVD) and related methods in textile industry. The European Physical Journal Applied Physics, 71(3), 75-79.

[2] Mattox, D. M. (2010). Handbook of physical vapor deposition (PVD) processing. William Andrew.

[3] Kula, P. (2000). Surface layer engineering, Monograph, Lodz University of Technology (Łodz). pp. 221-238.

[4] Burakowski, T., Wierzchoń, T. (1995). Metal surface engineering: Fundamentals, devices, technologies. Wydawnictwo Naukowo - Techniczne (Warsaw).

[5] Burakowski, T., Wierzchoń, T. (1998). Surface engineering of metals: Principles, equipment, technologies. CRC Press.

[6] Baptista, A., Silva, F. J. G., Poeteiro, J., Miguez, J., Pitno, G. (2018). Review sputtering physical vapour deposition (PVD) coatings: A critical review on process improvement and market trend demands. Coatings, 8(402), 2-22.

[7] Mattox, D. M. (2002). Physical vapor deposition (PVD) processes. Metal Finishing, 100(Supplement 1), 394-408

[8] Blicharski, M. (2009). Surface engineering. Wydawnictwa Naukowo - Techniczne Sp. z o.o. (Warsaw).

[9] Dobrzański, L. A. (2007). Basics of shaping the structure and properties of metal materials. Silesian University of Technology Publishing (Gliwice).

[10] Ziaja, J. (2012). Monograph, scientific works of the institute of electrical engineering and electrotechnology at the Wrocław University of Technology: Thin-film metallic and oxide structures. Properties, Technology, Application in Electrical Engineering (Wroclaw), pp. 15-37.

[11] Baptista, A., Silva, F. J. G., Poeteiro, J., Miguez, J., Pitno, G., et al. (2018). On the Physical Vapour Deposition (PVD): Evolution of magnetron sputtering processes for industrial applications. Procedia Manufacturing, 17, pp. 746-757.

[12] Oziomek, M., Wilczyński, W. (2009). Appliction of Ni-Fe thin films for shieldings of electromagnetic fields. Prace Instytutu Elektrotechniki (in Polish), 241, 40-48.

[13] Bula, K., Koprowska, J., Janukiewicz, J. (2006). Application of cathode sputtering for obtaining ultra-thin metallic coatings on textile products. Fibres \& Textiles in Eastern Europe, 14(5) (59), 75-79.

[14] Proudnik, A., Zamastotsky, Y., Siarheyev, V., Siuborov, V., Stankevich, E., et al. (2012). Electromagnetic interference shielding properties of the $\mathrm{Cu}, \mathrm{Ti}$ and $\mathrm{Cr}$ coatings deposited by Arc-PVD on textile materials. Przegląd Elektrotechniczny (in Polish), No. 6, pp. 81-83.

[15] Susek, W., Stanisławek, S. (2018). Study of innovation special textile clothing materials properties in the microwave range. Elektronika: Konstrukcje, Technologie, Zastosowania (in Polish), 59(6), 6-8.

[16] Ziaja, J., Jaroszewski, M., Lewandowski, M., Sasuła, M. (2018). Flexible materials used in electromagnetic field shielding), Przegląd Elektrotechniczny (in Polish), 10, ISSN 0033-2097.

[17] Ziaja, J., Koprowska, J., Janukiewicz, J. (2008). Using plasma metallisation for manufacture of textile screens against electromagnetic fields. Fibres \& Textiles in Eastern Europe, 16(5) (70), 64-66.
[18] Jaroszewski, M., Pospieszna, J., Ziaja, J. (2010). Dielectric properties of polypropylene fabrics with carbon plasma coatings for applications in the technique of electromagnetic field shielding. Journal of Non-Crystalline Solids, 356(11-17), 625-628.

[19] Kubsz, I. (2011). Modern electroconductive textiles produced by the method of physical vapour deposition (pvd), Przegląd Włókienniczy - Włókno, Odzież, Skóra (in Polish), 7-8, 44-48.

[20] Korzeniewska, E., Józwik, J., Zawiślak, R., Krawczyk, A., Michałowska, J. (2017). Resistance of metallic layers used in textronic systems to mechanical deformation. Przegląd Elektrotechniczny (in Polish), 12, 111-114.

[21] Koneczny, C. (2016). Properties of thin conductive layers produced on composite textile structures using the method of thermal vacuum deposition, doctoral dissertation under the supervision of dr hab. Eng. Ryszard Pawlak, prof. TUL, 2016, Technical University of Lodz.

[22] Pawlak, R., Korzeniewska, E., Koneczny, C., Hałgas, $B$. (2017). Properties of thin metal layers deposited on textile composites by using the PVD method for textronic applications. Autex Research Journal 17(3), 229-237.

[23] Pawlak, R., Korzeniewska, E., Frydrysiak, M., Zięba, J., Tęsiorowski, Ł., et al. (2012). Using vacuum deposition technology for the manufacturing of electro-conductive layers on the surface of textiles. Fibres \& Textiles in Eastern Europe, 20(2)(91), 68-72.

[24] Deng, B., Wei, Q., Gao, W., Yan, X. (2007). Surface functionalization of nonwovens by aluminum sputter coating. Fibres \& Textiles in Eastern Europe, 15(4) (63), 90-92.

[25] Silva, N. L., Gonçalves, L. M., Carvalho, H. (2013). Deposition of conductive materials on textile and polymeric flexible substrates. Journal of Materials Science: Materials in Electronics, 24(2), 635-643.

[26] Yuan, X., Wei, Q., Chen, D., Xu, W. (2015). Electrical and optical properties of polyester fabric coated with Ag/TiO2 composite films by magnetron sputtering. Textile Research Journal, 86(8), 887-894.

[27] Depla, D., Segers, S., Leroy, W., Van Hove, T., Van Parys, M. (2011). Smart textiles: An explorative study of the use of magnetron sputter deposition. Textile Research Journal, 81(17), 1808-1817.

[28] Wei, Q., Yu, L., Hou, D., Huang, F. (2008). Surface characterization and properties of functionalized nonwoven. Journal of Applied Polymer, Science, 107, 132137.

[29] Nowak, I., Krucińska, I., Januszkiewicz, Ł. (2019). Metallic electroconductive transmission lines obtained on textile substrates by magnetron sputtering. Fibres \& Textiles in Eastern Europe, 27(3) (135), 51-57.

[30] Scholza, J., Nockea, G., Hollsteinb, F., Weissbachb, A. (2005). Investigations on fabrics coated with precious metals using the magnetron sputter technique with regard to their anti-microbial properties. Surface \& Coatings Technology, 192, 252-256.

[31] Castro, C., Sanjines, R., Pulgarin, C., Osorio, P., Giraldo, S. A., et al. (2010). Structure-reactivity relations for DCmagnetron sputtered Cu-layers during E. coli inactivation in the dark and under light, Journal of Photochemistry and Photobiology A: Chemistry, 216(2-3), 295-302. 
[32] Chen, Y. H., Hsu, C. H., He, J. L. (2013). Antibacterial silver coating on poly(ethylene terephthalate) fabric by using high power impulse magnetron sputtering, Surface \& Coatings Technology, 232, 868-875.

[33] Chen, Y. H., Wu, G. W., He, J. L. (2015). Antimicrobial brass coatings prepared on poly(ethylene terephthalate) textile by high power impulse magnetron sputtering. Materials Science and Engineering: C, 48, 41-47.

[34] Zhai, Y., Liu, X., Xiao, L. (2015). Magnetron sputtering coating of protective fabric study on influence of thermal properties. Journal of Textile Science and Technology, 1(3), 127-134.

[35] Han, H. R., Kim, J. J. (2017). A study on the thermal and physical properties of nylon fabric treated by metal sputtering (Al, Cu, Ni). Textile Research Journal, 88(21), 2397-2414.

[36] Han, H. R., Park, Y., Yun, Ch., Park, C. H. H. (2018). Heat transfer characteristics of aluminum sputtered fabrics. Journal of Engineered Fibers and Fabrics, 13(3), 37-44.

[37] Meriç, Z. (2011). Antistatic applications: metal coated fibers by magnetron sputtering. Master of Science, Izmir Institute of Technology.

[38] Chodun, R., Wicher, B., Skowroński, Ł., NowakowskaLangier, K., Okrasa, S., et al. (2017). Multi-sided metallization of textile fibres by using magnetron system with grounded cathode. Materials Science Poland, 35(3), 639-646.

[39] Vančoa, M., Jan Krmela, J., Pešlováa, F. (2015). The use of $P V D$ coating on natural textile fibers. The 20th International Conference: Machine Modeling and Simulations, MMS 2015.
[40] Dietzel, Y., Przyborowski, W., Nockea, G., Offermannb, P., Hollsteinc, F., et al. (2000). Investigation of PVD arc coatings on polyamide fabrics. Surface and Coatings Technology, 135(1), 75-81.

[41] Wei, Q., Yu, L., Wu, N., Hong, S. (2008). Preparation and characterization of copper nanocomposite textiles. Journal of Industrial Textiles, 37(3), 275-283.

[42] Wei, Q., Wang, H., Deng, B., Xu, Y. (2010). Surface and interface investigation of Indium-Tin-Oxide (ITO) coated nonwoven fabrics. Journal of Adhesion Science and Technology, 24(1), 135-147.

[43] Lee, S. Y., Hong, T. M., Jin, D. Y., Lee, J. E., Lee, J. S., et al. (2015). Properties of aluminum deposited chemically recycled PET fabrics. Fibers and Polymers, 16(12), 26982703.

[44] Miśkiewicz, P., Frydrych, I., Pawlak, W., Cichocka, A. (2019). Modification of surface of basalt fabric on protecting against high temperatures by the method of magnetron sputtering. Autex Research Journal, 19(1), 36-43.

[45] Miśkiewicz, P., Frydrych, I., Pawlak, W. (2019). The influence of basalt fabrics modifications on their resistance to contact heat and comfort properties. International Journal of Clothing Science and Technology, 31(6), 874886.

[46] Miśkiewicz, P., Frydrych, I. Tokarska, M., Pawlak, W. (2019). Study on some thermal and electrical properties of basalt fabric modified with metal and ceramics as a result of magnetron sputtering. Polymers, 11(12), 1-15.

[47] Miśkiewicz, P., Frydrych, I., Makówka, M. (2020). Examination of selected thermal properties of basalt composites. Fibres \& Textiles in Eastern Europe, 2(140). 